\title{
A Comparison between Motherese in the West and in Chinese Mandarin
}

\author{
WANG Yurong, Lin Li
}

Department of English, College of Foreign Languages, China Three Gorges University, Yichang of Hubei Province, China

Email address:

wangyurongha@163.com (Wang. Y.),786343846@qq.com (Lin. L.)

\section{To cite this article:}

WANG Yurong, Lin Li. A Comparison between Motherese in the West and in Chinese Mandarin. International Journal of Language and Linguistics. Vol. 1, No. 4, 2013, pp. 117-123. doi: 10.11648/j.ij11.20130104.15

\begin{abstract}
Motherese, a name given to the restricted sort of language spoken by mothers to their children, could have an important role in affecting the rate of language acquisition. The way children acquire language in a miraculously short time is a topic of enormous current interest, stimulated by new technology which is currently enhancing our knowledge. Various studies have shown that those children who have been exposed to motherese are more likely to acquire the language at an accelerated pace. There are researches about this subject both in China and in the West, but a comparison of the similarities and differences between motherese in the West and in China has seldom been researched. This paper sets out to explore the similarities and differences between motherese in the West and in Chinese mandarin through a qualitative and a quantitative research. Through this study, it will be of great help to children's language development. Nowadays, with the development of the society, new mothers attach more importance to children's language development in order to found a good starting point. Meanwhile, many Chinese mothers want to create an English environment to their children by themselves. In this sense, this study can be of great significance.
\end{abstract}

Keywords: Motherese, Characteristic, Children, West, China, Language Development

\section{Introduction}

\subsection{The Definition of Motherese}

Ferguson (1977:209) gives a definition of motherese, that is the special way of talking to young children which differ more or less systematically from the normal form of the language used in ordinary conversation among adults, which is appropriate for use with young children. According to the Collins English Dictionary(2011), the definition of motherese is stated as follows: (linguistics) the simplified and repetitive type of speech, with exaggerated intonation and rhythm and often used by adults when speaking to babies. Motherese is also called Baby Talk, Child-Directed Speech(CDS) and Infant-Directed Speech(IDS) in some papers and studies. I prefer "motherese" because of its novelty.

\subsection{Motherese Hypothesis}

Studies of various kinds have addressed the role of the environment in child language acquisition. Case studies of children who have undergone severe isolation, such as Gene, indicate grossly delayed language and imply that exposure to language is a prerequisite for normal language growth. Correlational and experimental studies suggest that at least certain aspects of the speech adjustments adults make when speaking to children may influence the child's language development. However, other aspects of language appear to be impervious to variations in maternal language(Carroll, 2000)

The Motherese hypothesis states that there is a relationship between the speech adjustments adults make and children's language development (Gleitman et al. 1984) Osser (1975:303) writes "one direction is the necessary closer examination of the child's environment in order to locate possible sources of support for details of his language development". From these statements, we can find that language development is directly and mostly influenced by the language spoken around the child. When the child is born, the mother stays with him or her for most of the time and talks to him or her most of the time, so a kind of nonstandard form of language comes into being, which is termed motherese. According to Professor Katherine Demuth, director of the Child Language 
Laboratory at the center for language science linguistic department, "we use changes in pitch and rhythm when we talk to children, and we emphasize important words. These are what children usually learn and produce first". What the Professor described here is, in fact, motherese. This paper sets out to explore the similarities and differences between motherese in the West and in Chinese mandarin through a qualitative and a quantitative research. Through this study, it will be of great help to children's language development. Nowadays, with the development of the society, new mothers attach more importance to children's language development in order to found a good starting point. Meanwhile, many Chinese mothers want to create an English environment to their children by themselves. In this sense, this study can be of great significance.

\section{Literature Review}

\subsection{Research in the West}

\subsubsection{The Characteristics of Children's Language}

Table 1. Infraphonological interpretation of infant vocalizations at four ages (Oller, 2000)
According to Locke (1983:478), infants are stimulus-seeking animals. They can quickly learn to recognize their mother's face as well as her voice. In our daily life, we can find that when a crying child sees his/her mother or hears his/her mother's voice, he/she will stop crying. So, doing things to get the stimulation they want is of great importance. By at least three to four months, infants are aware of the relationship between some certain facial expressions and vocal activity.

According to Miller (1977: xxvii; cited in Fletcher and Mac Whinny, 1996: 283): "Young children have an unusual faculty for learning language, and it is well that they do, for we expect them to learn far more than we could self-consciously teach them ". Children learn to talk by listening when adults, especially their mothers, are talking, they are helping children learn to talk naturally and unconsciously. According to Oller(2000), very young infants are already actively involved in the learning process. As we can see from Table1.

\begin{tabular}{ccc}
$\begin{array}{c}\text { Ages } \\
\text { In months }\end{array}$ & $\begin{array}{c}\text { Global protophone } \\
\text { Categories mastered }\end{array}$ & $\begin{array}{c}\text { Principles of syllable } \\
\text { Well-formedness mastered }\end{array}$ \\
\hline $0-1$ & Quasivowels & Normal phonation \\
$2-3$ & Gooing & Articulation \\
& & Full resonance \\
$4-5$ & Marginal babbling, full vowels & Rapid format transition \\
& & \\
& Canonical babbling & \\
\hline
\end{tabular}

In the first month of children's life, they have the ability to differentiate different sounds; also they can understand intonation and words indicating objects. Then, they acquire language little by little and step by step. According to Piaget (1932), there are six stages of language acquisition. The first one is the crying stage, which lasts from the baby's birth until about three or six months old. During this stage, the baby discovers new sounds and simply expresses them by crying. The second one is the "babbling stage", which begins from three to seven months. From this time, the baby begins to repeat easy syllables, such as "dada", "papa", etc. Then appears the one-word stage when the child is nine to twelve months. They produce the first real word, such as "mummy", "daddy", etc. The next stage is called the two-word stage around the age of two. Children can express some grammatical sentences. The fifth stage is the multi-word stage when the child is three to four years old. The baby has acquired more words and is able to express him/herself.

\subsubsection{The Characteristics of Motherese}

The features of "Baby Talk" are: (1) special vocabulary, e.g. words like doggie (instead of a dog); (2) consonant 
cluster reduction, e.g. tummy instead of stomach; (3) reduplication; (4) deviant use of pronouns; (5) slowed pace; (6) the voice is quite often very low and the adults pay attention to the articulation of the words; (7) the intonation of the voice is singsong and the rhythm is marked by pauses to highlight cut-out sentences; (8) paraphrasing of sentences; (9) short sentences; (10) syntactically less complex sentences or simplification; (11) use of many repetitions of word sentences; (12) exaggeration of intonation(Chahine, 2003:66).

Elliot (1981:151) concludes that there are three features of motherese, which are paralinguistic features, syntactic features and discourse features. Paralinguistic feature means high pitch and exaggerated intonation; syntactic features include shorter mean length of utterance, fewer verb forms and modifiers, shorter mean proverb length, more verbless utterances, and more content words, fewer function words. Discourse features consist of more interrogatives and imperatives, more fluent and intelligible speech and more repetitions. It is similar to the features mentioned above.

We can see that motherese is a kind of language which can adapt to children's comprehension level and also their pronunciation style. These features can be, in a sense, similar to children's language. So, motherese will inevitably have an influence on children's language development.

\subsubsection{Mother's Special Role in Children's Language Development}

In language acquisition, the environment input is very important. Without input from the environment, the infant will apparently not successfully acquire the ability to produce the sounds of its language no matter how much physical maturation proceeds. Mother, as the most intimate person with the child, will inevitably have a great influence on their child. So motherese will surely have a great effect on children's language development.

In our daily life, it is very common to hear adults speaking to their children as if they were children themselves, especially mothers. "Mothers adapt more easily their speech to the baby than fathers and the former even use a too "babyish" register and speak in a silly manner"(Chahine, 2003: 62). In a sense, mothers are regarded as playing a more important role than fathers by many specialists. "Since the mother is the primary socializing agent in most instances, the learning takes place in the context of the mother-child communication system" (Olim, 1975:309). It seems that mothers use different strategies from fathers in talking to children.

DeCasper and Fifer (cited in Fletcher and Mac Whinny, 1980: 208 ) also point out that "in the first several days of life, infants also reveal a listening preference for their mother's voice"(208). In 1987, Fernald and Kuhl used an operant head-turning technique to testify whether infants have a listening preference or not. They found that four-month-olds prefer to hear the higher fundamental frequency and more exaggerated frequency variations associated with infant directed speech. They think it is the inherent design features of the auditory system that counts. "Exaggerations of pitch seem to hold a certain universal appeal, presumably as a result of underlying biological mechanisms that have evolved to serve onto genetic functions" (Fernald, 1992: 289). Large variations in vocal pitch are a key feature of motherese in many languages and cultures. So, they concluded that infants indeed have a listening preference to their mothers.

Since infants cannot express themselves, how can mothers identify what their babies want? Like other primate mothers, they use vocal information to identify their infants, and to gain information about their health and emotional state. Mothers pay close attention to the voices of their infants from the first postnatal moments. Infants pay close attention to their mother's voice as well.

Mothers stay with their children most of the time, so they are the ones who know what their children really need, not only food or drink, but also their need to communicate with special language in different periods. Mothers should be very sensitive to their children's linguistic attempts, talking to them all the time. This can be a starting point to influence their children's language. This is beneficial to the later development of children's language.

Apart from this, features of the mother's speech can also shed some light on children's language. According to Chahine (2003), there are six features of mother's speech: (1) Repeat a lot what the child says; (2) speak a lot with the child; (3) use simple words; (4) try to speak correctly; (5) stress the words; (6) generally ask more questions than fathers (2003:63).

All these statements show that mothers' speech plays a pivotal role in child language development. The reasons are as follows: first, children have a listening preference for their mothers' voice; second, mother is the very one who is most sensitive about children's linguistic attempts and can respond them in an appropriate way; third, the special characteristics is the best and most attractive stimuli to children.

\subsection{Research in China}

In China, some research has been done on this subject and there have been some new findings. Some Chinese researchers focus their attention on the lexical tone in mandarin motherese. Some researchers pay more attention to the influence of motherese at different levels.

For example, Chen Min (2009) carried out an empirical study to find out whether motherese exists or not; she studied conversations between adults and conversations between adult and children at the level of sentences. From her case studies, she draws the conclusion that motherese does exist.

Furthermore, Chen Min (2005) writes on the issue of fine-tuning of linguistic complexity in child directed speech. She studied a Mandarin-speaking mother's monthly conversations with her child and made a comparative study 
between the English mother-child conversations and the Mandarin-speaking mother-child conversations. She draws the conclusion that it is the children themselves that make a great contribution to language acquisition, and mothers only show slight variation. Her study is in great detail and she compares the process from the specific word acquisition to sentence acquisition.

Huei-Mei Liu(2007) analyze the lexical tone in mandarin infant directed speech from the perspective of acoustic analysis. Through his analysis, mandarin-speaking mothers preserve the spectral and temporal correlates of lexical tone that are necessary to convey the correct lexical meaning of each syllable in IDS.

According to Yin Jing (2012), motherese includes speech, gesture and "motionese", a word that she invented to simplify the language of their actions or movements. In recent years, the research has been done more and more on motionese. She emphasizes the importance of "motionese" and draws the conclusion that the proper use of motionese can be of great help to the early vocabulary acquisition.

There are also some studies on child language at different levels, such as word level, sentence level, etc. Whether in the West or in China, scholars seem to reach agreement on the features of motherese and the influence of motherese on child language development, so the focus is gradually shifting to the practical influence in the vocabulary or sentence level and the sub-branches of motherese, such as motionese.

In this paper, I will try to compare the similarities and differences between the motherese of Western children and Chinese children from the aspect of speech and motionese.

\section{Quantitative Study}

\subsection{Research Question}

What are the similarities and differences of motherese in the West and in Chinese mandarin?

\subsection{Subjects}

I will find 20 mothers in China and 20 mothers in the West, and all of them are just having their babies. Their babies are all at the age of one month to 5 years old. I will study the similarities and differences of motherese in the
West and in China and also the functions of motherese.

\subsection{Methodology}

I will further my study by an interview. I will interview 20 Chinese mothers and 20 western mothers with the following questions: (1) What are the first words of their children? (2) What kind of words did you use in referring to an object? (3) What are the characteristics when talking to your children? Then, I will write down their answers for analysis.

\subsection{Results}

Through the interview, $90 \%$ mothers both in China and in the west point out that the first language their baby saying is $b a, p a, m a, b a b a$, mama, papa, dada and so on. In referring to the objects, they prefer to use the onomatopoeic words, such as dingdong for the door, choo-choo for the train etc. When talking to their children, $97 \%$ mothers say that they frequently use repetitions, such as wawa for water, fanfan for rice and so on. By analyzing their remarks, I draw a conclusion and make a comparison between motherese in the west and in Chinese mandarin in great detail.

\section{A Comparison on Western and Chinese Motherese}

\subsection{Similarities}

\subsubsection{Similarities of Words}

There are some similarities in the aspect of speech, because many special words are used both in English and Chinese. Although English and Chinese belong to different language families, there are still some similarities in motherese.

First, the first sound starts with a consonant (C) and then a vowel (V) both in the West and in Chinese mandarin. For example, $b a(\mathrm{CV}), p a(\mathrm{CV}), l a(\mathrm{CV})$, etc. are firstly appeared in infants' languages. Then, the CVCV structure begin to appear, for instance, mama (CVCV), baba (CVCV), papa (CVCV), and dada (CVCV), etc. are the first words both in Chinese and in English. As we can see from Table 2.

Table 2. The structure of first words in the west and in Chinese mandarin.

\begin{tabular}{ccc}
\hline In the West & In Chinese mandarin \\
\hline $\mathrm{CV}$ & Ma, ba, pa, la, na, etc. & Ma, pa, fa, ba, la, etc. \\
$\mathrm{CVCV}$ & Mama, papa, dada, etc. & Mama, baba, gege, didi, etc. \\
\hline
\end{tabular}


Second, onomatopoeic words are all widely used in motherese. They are very vivid, so they can draw children's attention and they are easy for children to imitate and remember. In English, for example, choo-choo is used to stand for a train; moo-moo is used to stand for a cow; bow-wow is used to stand for a dog, etc. In Chinese, for instance, kacakaca is used to stand for a train; miao-miao is used to stand for a cat; wang-wang is used to stand for a dog; mie-mie is used to stand for sheep and bugu-bugu for a bird, etc. Although different onomatopoeic words are used to stand for the same thing, it still shows the wide use of onomatopoeic words in motherese. Through Table 3, I will illustrate it clearly.

Table 3. The use of onomatopoeic words in the west and in Chinese mandarin.

\begin{tabular}{|c|c|c|}
\hline $\begin{array}{c}\text { Onomatopoeic } \\
\text { words }\end{array}$ & In the west & In Chinese mandarin \\
\hline train & Choo-choo & Kaca-kaca \\
\hline cow & Moo-moo & Moo-moo \\
\hline cat & Miao-miao & Miao-miao \\
\hline $\operatorname{dog}$ & Bow-wow & Wang-wang \\
\hline
\end{tabular}

Third, many repetitions are used in motherese. For example, in "the cake is yum-yum", the word yum-yum is a duplicated word means yummy. In British English, quick-quick is used in motherese which means doing things quickly; in South African English, doedoes is used to stand for going to bed. This is also the case in Chinese. For example, mothers use fanfan to stand for rice; shuishui for water; tangtang for candy and cheche for car. This is the most pervasive phenomenon in Chinese motherese.

\subsubsection{Similarities of sentences}

Sentences are too long and too difficult for infants to understand, so shorter mean length of utterances are both used in English and Chinese. For example, in English, many utterances are verbless. "Mama apple" means "mum, I want to eat an apple". "Daddy dog" means "daddy, I want to play with the dog". "Baby milk" means "baby, it's time to drink some milk". This is also the case of Chinese, for instance, "baobao, fanfan" is used by mothers to ask the baby to have dinner. "Mama guoguo" means "mum, I want to eat fruits". Although, these sentences are ungrammatical, they play an important role in motherese.

\subsubsection{Similarities of Intonation}

English and Chinese are languages which belong to two different families, but there are still some similarities on intonation. Both English motherese and Chinese motherese are slowly in a low, quiet voice, in which case children can feel comfortable and eager to talk.

\subsubsection{Similarities of Motionese}

When mothers are talking to their children, they will naturally make some gestures, facial expressions and so on. This movement is a kind of language called motionese. Both in English and Chinese, mothers use some movements frequently in order to arouse children's attention and help them to better understand their utterances. For instance, mothers often nod their head with a smile face, which will encourage children to talk.

\subsection{Differences}

\subsubsection{Differences of Words}

Mothers always call their children by their nicknames. In English, words in shortened form are used. For example, Liz is the nickname of Elizabeth; Tom is the nickname of Thomas; Tess is the nickname of Teresa, etc. However, in Chinese, their nickname is always the repetition of the last character of the name. For instance, Li Dan is called by her mother "dandan"; Wang Rong is called "rongrong"; Chen Ting is called "tingting", etc. This is very common in motherese.

There is another difference. In English, adding a terminal /i/ sound at the end, usually written and spelled as /ie/, /y/, or /ey/, is a common way to form a diminutive which is often used as part of motherese, which is used by mothers to show intimacy. For instance, they use horsey for horse, kitty for cat, doggy for dog, milky for milk, drinky for drink, poopy for poop and ducky for duck, etc. In Chinese Mandarin, there is no such kind of change in Chinese. The 
reason lies in the differences of two different languages.

\subsubsection{Differences of Intonation}

Their exaggeration of intonation is different. In English, intonation mainly lies in the sentences, for example, in the sentence "you are so clever", the last two words are stressed. The rhythm lies in the whole sentence. In Chinese, it is different. Chinese is a kind of tonal language; the intonation lies in every single word. For example, in the word cong ming, the first word is stressed. The rhythm lies in words or phrases.

\section{The Significance of the Research}

Nowadays, with the development of the society, new mothers attach more importance to children's language development in order to found a good starting point. Meanwhile, many Chinese mothers want to create an English environment to their children by themselves. In this sense, through the comparison of the similarities and differences of motherese in the west and in Chinese mandarin, mothers can choose a good way by using different motherese to communicate with their children both in English and in Chinese, which can be of great significance in stimulating children's language acquisition system and also can be of great help to children's cognitive development. In China, more and more mothers attach more importance to children's language input from the very beginning in order to promote its ability. So, some methods are needed. This paper serves as a guidance for them.

Meanwhile, many mothers in the West like Chinese very much, and they want their children to learn Chinese while acquiring their mother tongue. Many Confucius schools are built in the west, and it aims to teach students to learn Chinese. If mothers in the west pay more attention to the similarities and differences between motherese in their own language and in Chinese, It may be a good try.

\section{Conclusion}

Mother, as the most intimate person with the child, has a great influence on their children in every aspects, including language. Motherese is a special language used by their mothers to their children, which can be in line with the characteristics of children's language. Both in English and in Chinese mandarin, there are some similarities and also differences in the characteristics of motherese. Whether in English or Chinese mandarin, motherese has a special role in children's language development, which can be of great help to the later development of children's language. Through this study, we clearly understand the influence of motherese on their children's language development. Nowadays, with the widespread use of English, in China, many mothers want to expose their newly born children to an English environment. New mothers attach more importance to children's language development in order to found a good starting point. Meanwhile, many Chinese mothers try their best to create an English environment to their children by themselves. In this sense, this study can be of great significance. It will be a guidance for new mothers. By using the similar pars, they can give them stimuli both in Chinese and in English. By bearing the differences in their mind, they can use different stimuli respectively.

\section{References}

[1] Alison, J. E. (1981), Child language. Cambridge textbooks in linguistics.

[2] Carroll, D. W. (1999), Psychology of Language(M). Brooks/Cole/Thomson Learning Asia.

[3] Ferguson, C. A (1977). "Baby talk as a simplified register", In: Snow, C.E and Ferguson, C,A (eds.), Talking to Children: Language Input and Acquisition, Cambridge: Cambridge University Press, pp. 209-235.

[4] Fernald, A. (1984) The Perceptual and affective salience of mothers' speech to infants. Norwood, NJ: Ablex.

[5] Gleitman, L. R., Newport, E.L. and Gleitman, H. The current status of the motherese hypothesis(J). Journal of Child Language, 1984, (11):43-79.

[6] Huei-Mei, L.(2007), Acoustic Analysis of Lexical Tone in Mandarin Infant-Directed Speech(J). Language Science, America.

[7] Locke, J. L. (1983). "Development of the Capacity for Spoken Language", In: Paul Fletcher \& Brian MacWhinny, The Handbook of Child Language, Blackwell.

[8] Osser, H. (1975). "Biological and Social Factors in Language Development", In: Rogers, Sinclair(ed.), Children and Language, Readings in Early Language and Socialization, London: Oxford University Press, pp. 289-307.

[9] Olim, E. G. (1975), "Maternal Language Styles and Cognitive Development", In: Rogers, Sinclair(ed.), Children and Language, Readings in Early Language and Socialization, London: Oxford University Press, pp. 309-326.

[10] Oller, D.K., (1978). Infant vocalizations and the development of speech. Allied Health and Behavioral Science 1, 523-549.

[11] Paul, F., et al. (1023-1925), The Handbook of Child Language, Blackwell.

[12] Patrick, H. (2011), Collins English Dictionary. HarperCollins Publishers LLC.

[13] Yasmine, C. (2003). Child Language Acquisition: "The role of socialization in the acquisition of language". Annee academique.

[14] 陈敏 (Chen Min) (2005), The issue of fine-tuning of linguistic complexity in child directed speech[J]. Hunan University Press.

[15] 陈敏 (Chen Min) (2009), Empirical study on the existence of child directed speech [J]. Journal of Shaoyang University (Social Science Edition). 
[16] 尹静 (Yin Jing) (2012), Motionese: a new advance in the study of motherese[J]. Chinese Journal of Special Education.

[17] http://en.wikipedia.org/wiki/Baby talk. 